\title{
Gênero, educação e desenvolvimento: os Objetivos de Desenvolvimento do Milênio de número dois e três na América Latina
}

Gender, education and development: Millennium Development Goals number two and three in Latin America

Thaís G. A. de Moraes

\begin{abstract}
Resumo
O presente artigo busca analisar o impacto dos Objetivos de Desenvolvimento do Milênio (ODMs) número dois e três na América Latina. Primeiramente, irá expor as relações existentes entre os ODMs dois (atingir o ensino básico universal) e três (promover a igualdade de gênero e a autonomia das mulheres). Em segundo lugar, apresentará peculiaridades da realidade latino-americana contemporânea no tocante à igualdade de gênero na educação. A partir disso, analisará uma política pública muito disseminada na região, que tem tido relevante influência na transformação do cenário latino-americano quanto ao acesso à educação com igualdade de gênero: os Programas de Transferência Condicional de Renda. Espera-se, com esta pesquisa, contribuir para a atuação dos governos, sociedade civil e setor privado da América Latina na efetivação dos ODMs dois e três.
\end{abstract}

Palavras-chave: gênero - educação - América Latina - desenvolvimento - sociedade internacional.

\begin{abstract}
This article aims to analyze the impact of the Millennium Development Goals (MDGs) two and three in Latin America. Firstly, it will explore the relations between the MDGs two (achieve universal primary education) and three (promote gender equality and empower women). Secondly, it will present the particularities of contemporary Latin America in what relates to gender equality in education. Finally, it will analyze a very common policy in the region, which has been considerably impacting Latin America with regards to access to primary education and gender equity: the Conditional Cash Transfer Programs. This research paper's goal is to contribute to the achievement of the MDGs two and three in Latin America by encouraging actions from governments, civil society and the private sector.
\end{abstract}

Key words: gender - education - Latin America - development - international society.

Estudante de graduação em Direito da Universidade Federal de Pernambuco, Brasil. Concluiu um semestre de sua graduação como bolsista do Programa Líderes Emergentes nas Américas, na Universidade de Saint Mary, Canadá, onde estudou Ciência Política e Sociologia. 


\section{INTRODUÇÃO}

Em 2000, representantes de 189 países reuniram-se na Cúpula do Milênio da Organização das Nações Unidas (ONU). Nesta ocasião, chegou-se a um consenso quanto à elaboração dos Objetivos de Desenvolvimento do Milênio (ODMs), resultado de diversas reuniões internacionais ocorridas ao longo da década de 1990 como, por exemplo, a Conferência sobre o Meio Ambiente no Rio de Janeiro, a Conferência sobre Direitos Humanos em Viena e a Conferência Mundial sobre a Mulher em Pequim. Resultados destas conferências, os ODMs podem ser definidos como um conjunto de objetivos a serem atingidos até 2015, que têm como foco problemas prioritários de ordem global, como a pobreza, a desigualdade de gênero e a fome (Laurenti, 2005).

Os mencionados objetivos consistem em: 1) Erradicar a extrema pobreza e a fome; 2) Atingir o ensino básico universal; 3) Promover a igualdade de gênero e a autonomia das mulheres; 4) Reduzir a mortalidade na infância; 5) Melhorar a saúde materna; 6) Combater o HIV/AIDS, a malária e outras doenças; 7) Garantir a sustentabilidade ambiental; 8) Estabelecer uma parceria mundial para o desenvolvimento ${ }^{2}$. Estes objetivos foram, em seguida, desenvolvidos com mais detalhes e quantificados em indicadores numéricos para que fosse possível um adequado monitoramento quanto à efetivação dos ODMs.

Após alguns anos da adoção dos ODMs, análises publicadas por organizações internacionais, como o Banco Mundial, começaram a chamar a atenção para a impossibilidade de atingir tais objetivos, se fossem mantidas as tendências históricas. Isto é, se não houvesse uma mudança de comportamento por parte dos atores principais da sociedade internacional (notadamente, Estados, organizações internacionais e sociedade civil). Barroso (2004) afirma que, se não houver sucesso na efetivação dos ODMs, não apenas os países menos desenvolvidos seriam afetados, mas sim toda a sociedade internacional. Nações teriam que lidar com sua incapacidade para resolver problemas sócio-econômicos que criam e perpetuam condições sub-humanas de sobrevivência, as quais são incompatíveis com a noção mesma de civilização.

Ainda assim, a relevância dos ODMs permanence sendo objeto de questionamento para muitos. É possível que haja razões legítimas para definir tais objetivos principalmente como "a cloud of soft words, good intentions and moral comfort (...) that give well-meaning persons in the north-west a sense of solidarity and purpose" (Saith, 2006: 1167). Entretanto, não há dúvidas de que, para a saúde, bem-estar e até sobrevivência (em casos mais extremos, como o dos moradores das "favelas" ou "pueblos jóvenes" na América Latina) da população em grande parte do mundo, atingir os ODMs, de maneira holística, sólida e sustentável, é fundamental.

2 United Nations. We can end poverty 2015: Millenium Development Goals - a gateway to the UN's work on the MDGs (2010). 
Devido à necessidade de estabelecer limites metodológicos para analisar um assunto de tamanha amplitude e complexidade, o foco deste artigo será: tematicamente, a relação entre o ODM dois (atingir o ensino básico universal) e três (promover a igualdade de gênero e a autonomia das mulheres); e geograficamente, a América Latina -incluindo toda a América do Sul, América Central (Continental e Insular) e o México. A região apresenta particularidades interessantes quanto a seu status no mundo em desenvolvimento e quanto aos notáveis avanços que tem alcançado nos anos recentes em relação aos ODMs dois e três.

Neste contexto, este artigo objetiva responder às seguintes perguntas: De que forma os Objetivos de Desenvolvimento do Milênio de número dois e três se relacionam? Qual o cenário da América Latina neste contexto? Que tipo de ações ou políticas públicas têm sido propostas por organizações locais e governos nacionais para lidar com estas questões na região -e ainda, que tipo de impactos tiveram (ou espera-se que tenham) tais ações na realidade da região?

Primeiramente, este artigo argumentará que a relação entre os ODMs dois e três deve-se à potencial redução na mortalidade infantil, fertilidade das mulheres e subnutrição das crianças e jovens, assim como a melhoras na educação para as próximas gerações e crescimento econômico, o qual pode atuar na quebra do ciclo inter-geracional de pobreza.

Em segundo lugar, apresentará algumas particularidades da América Latina em relação a outros cenários regionais de países em desenvolvimento. Em suma, a situação da América Latina é intrigante, porque a região aparenta ter atingido a igualdade de gênero dos jovens matriculados nas escolas antes do tempo previsto para a concretização dos ODMs. Entretanto, a região ainda é afetada por problemas estruturais que impedem a efetivação plena dos objetivos dois e três - como o machismo, a segmentação entre homens e mulheres no mercado de trabalho, qualidade precária do sistema educacional público e altos índices de deserção escolar no Ensino Médio.

Em terceiro lugar, será apresentado um exemplo de política pública, usada pela maioria dos países da região, que tem tido um impacto variável em diferentes nações quanto à promoção da igualdade de gênero e atingir o ensino básico universal: os Programas de Transferência Condicional de Renda.

Com relação aos materiais e métodos, os dados serão obtidos a partir de relatórios elaborados por organizações internacionais intergovernamentais, como a ONU, e também por bancos de fomento ao desenvolvimento, como o Banco Mundial e o Banco Interamericano de Desenvolvimento. Este artigo trará uma abordagem interdisciplinar, pois buscará dialogar com artigos acadêmicos, pesquisas e publicações variadas de diversas áreas das ciências sociais, como, por exemplo, a ciência política, a sociologia e a economia. 


\section{INTERSEÇÕES ENTRE OS OBJETIVOS DE DESENVOLVIMENTO DO MILÊNIO DOIS E TRÊS}

Koffi Annan, ex-Secretário Geral da ONU, deu início ao Projeto do Milênio, cujo objetivo era fornecer suporte técnico para a concreção dos ODMs. O projeto foi organizado a partir de grupos de trabalho, formados tanto por representantes da ONU, como por organizações governamentais, não-governamentais e privadas. Os objetivos dois e três foram reunidos no mesmo grupo de trabalho. Esta união faz sentido já que, por um lado, um dos principais indicadores da igualdade de gênero é o acesso à educação e, por outro lado, entre os indicadores principais quanto ao acesso à educação, encontra-se a paridade entre meninos e meninas matriculados em instituições de ensino básico.

Além do valor intrínseco que tem enquanto um objetivo de desenvolvimento, a educação é fundamental para possibilitar indivíduos a aproveitarem as oportunidade que são criadas com o desenvolvimento. Atualmente, há uma significante desigualdade de gênero na educação, em diversas partes do mundo. Esta situação vai de encontro à igualdade de gênero como um objetivo em si mesmo, conforme reconheceu a Convenção para Eliminação de Todas as Formas de Discriminação contra a Mulher (CEDAW), assinada e ratificada pela maioria dos países em desenvolvimento 3 .

Assim, pode-se dizer que a sociedade internacional reconhece tanto a educação como a igualdade de gênero como fins em si mesmos, pois representam valores e princípios que são protegidos pelos Direito Internacional. Para além disso, porém, a importância da igualdade de gênero na educação -um aspecto crítico do bemestar- é reforçada por seus efeitos instrumentais para o desenvolvimento. Isto é, não apenas são a educação e a igualdade e gênero fins em si mesmos: são também meios para outros fins desenvolvimentistas. De acordo com Abu Ghaida e Klasen (2004), a manutenção da desigualdade de gênero impedirá a redução na mortalidade infantil, na fertilidade feminina e na subnutrição, assim como reduzirá os ganhos na educação da próxima geração.

Isto se deve à correlação, indicada por modelos econômicos de fertilidade, existente entre fertilidade feminina e o custo de oportunidade do tempo das mulheres e do seu poder de barganha. De forma análoga, modelos produtivos de saúde no ambiente doméstico enfatizam que os anos de educação relacionam-se de forma diretamente proporcional à habilidade da mãe em promover a saúde de seus filhos. Ademais, a educação confere à mulher um maior poder de barganha junto ao resto da família, o que torna suas decisões sobre distribuição de recursos dentro do lar mais relevante, e tende a favorecer a alocação de recursos em favor da saúde e nutrição das crianças.

A disparidade de gênero na educação também tem impactos negativos no crescimento econômico. De acordo com a pesquisa empírica realizada por Abu Ghaida

Abu Ghaida and Klasen (2004). The Cost of Missing the Millennium Development Goal on Gender Equity. 
e Klasen (2004), as seguintes conexões podem ser identificadas entre a desigualdade de gênero e a educação:

a) A redução do nível médio do capital humano disponível na economia: Uma vez que meninos e meninas apresentam uma distribuição similar de habilidades natas, a desigualdade de gênero na educação significa que a habilidade e talento médios daqueles que têm acesso à educação é reduzida em relação a um cenário no qual meninos e meninas tivessem iguais oportunidades educacionais. Assim, a disparidade de gênero na educação reduz o nível médio do capital humano presente na economia e, portanto, atua como obstáculo ao crescimento econômico;

b) O efeito combinado entre disparidade de gênero na educação e disparidade de remuneração: Na maioria dos países do mundo, há disparidade entre homens e mulheres quanto à remuneração pelo mesmo trabalho realizado. Tal disparidade pode ser lucrativa para empregadores, pois podem acelerar o crescimento econômico se investirem em indústrias que empregam predominantemente mulheres, como no caso de muitos países Asiáticos no fim do século XX. Isso só seria possível se as mulheres forem suficientemente educadas para ingressarem no mercado de trabalho. Entretanto, buscar o crescimento econômico através desta estratégia é incompatível com a motivação geral dos ODMs. Afinal, se é verdade que o crescimento econômico pode melhorar o bem-estar geral da população, é igualmente verdade que buscar o crescimento econômico sem levar em consideração o desenvolvimento social e humano pode ter conseqüências perversas para as minorias políticas e os grupos sociais mais vulneráveis.

c) Ofator de externalidade direta de desigualdade de gênero na educação: Acredita-se que a educação da mulher tem impactos diretos na quantidade e qualidade da educação das crianças, uma vez que mães educadas têm mais poder de barganha no lar e, com isso, mais capacidade de oferecer à criança apoio e um ambiente favorável para sua criação. Isto levaria a uma melhoria do nível educacional da população e, com isso, ao crescimento econômico.

d) A externalidade indireta operando através de efeitos demográficos: Decréscimo na taxa de fertilidade e a conseqüente redução na população de crianças aumentam a proporção de trabalhadores disponível na população total. Entre outros efeitos, isso diminui o fardo de dependência (mais trabalhadores têm que compartilhar seus salários entre menos dependentes, aumentando a média da renda per capita), permitindo à população um aumento no seu nível de poupança, o que impulsiona o crescimento econômico. Como a educação de mulheres foi um dos fatores centrais a que se atribui o declínio da taxa de fertilidade, tal fator pode ser responsável, em grande parte, pelo boom econômico gerado em muitos países a partir desta transformação demográfica. 
Também é importante ressaltar a relação dos ODMs dois e três com os demais objetivos, como bem salientam Abu Ghada e Klasen (2004). Considerando a relevância destas conexões, a disparidade de gênero na educação pode causar diversos problemas de caráter instrumental para os formuladores de políticas públicas, na medida em que compromete o progresso em relação a outros objetivos de desenvolvimento -inclusive outros ODMs.

Além de ser central para o sucesso dos ODMs de número dois a sete, especificamente aqueles relacionados à redução da mortalidade materna e à erradicação do HIV e outras doenças, a redução da disparidade de gênero na educação é também fundamental para o sucesso do Objetivo de número um (erradicar a pobreza extrema e a fome). Todos os indicadores de pobreza atuais referem-se a famílias, no lugar de indivíduos. Portanto, não há um indicador desagregado confiável que possa aferir o nível de pobreza individual por gênero. Apesar disso, tem-se o dado de que famílias lideradas por mulheres classificam-se como mais pobres do que as lideradas por homens. Esta constatação sugere fortemente a importância de investir na igualdade de gênero e na autonomia das mulheres para erradicar a pobreza extrema. ${ }^{4}$

O Banco Interamericano de Desenvolvimento (BID) confirma que investir em mulheres em famílias pobres apresenta altos retornos para o bem-estar infantil e salienta que tais investimentos são uma ferramenta eficaz na quebra do ciclo inter-geracional de transmissão da pobreza e, portanto, no combate à pobreza estrutural da América Latina. ${ }^{5}$

Mesmo com todas as interseções entre os ODMs dois e três, é inegável que a questão do acesso universal à educação básica, não apenas inclui, mas vai além da questão da igualdade de gênero, e vice-versa. Contudo, a relação entre estes dois objetivos e a influência que o sucesso de um exerce no sucesso de outro são deveras importantes para o alcance de um bom índice de desenvolvimento humano para a sociedade mundial, uma vez que ambas as questões estão na raiz de muitos problemas sociais sofridos tanto por países desenvolvidos como em desenvolvimento.

\section{AMÉRICA LATINA: UM CENÁRIO PECULIAR NO CONTEXTO DOS PAÍSES EM DESENVOLVIMENTO}

Tipicamente, países em desenvolvimento apresentam indicadores insatisfatórios de igualdade de gênero e acesso à educação básica. Reconhece-se, pois, que atingir os ODMs deve ser uma prioridade para todos os países da sociedade internacional. Porém, se a meta é alcançar os ODMs no ano de 2015, pensar em soluções para os

$4 \quad$ Bouillon, Cesar P (2005). The Millennium Development Goals in Latin America and the Caribbean: Progress, priorities and IDB support for their implementation.

5 Bouillon, Cesar P (2005). The Millennium Development Goals in Latin America and the Caribbean: Progress, priorities and IDB support for their implementation. 
problemas em tela faz-se especialmente urgente para os países em desenvolvimento, os quais tendem a estar mais distantes dos objetivos estabelecidos.

Neste contexto, a América Latina apresenta uma intrigante particularidade: apesar de ser tipicamente classificada como parte do mundo 'em desenvolvimento', a região atingiu igualdade de gênero no acesso à educação antes do prazo estabelecido. Na verdade, pesquisas citadas por relatórios da ONU mostram que durante a década de 1990, antes mesmo da elaboração dos ODMs, o acesso igualitário (no tocante ao gênero) à educação básica já havia sido alcançado na região. A quantidade de meninos e meninas matriculados nas instituições de ensino básico era equilibrada. Nas instituições de nível médio e superior, havia mais meninas matriculadas do que meninos. ${ }^{6}$ O gráfico abaixo demonstra que a América Latina foi uma das regiões que mais avançou no Índice de Igualdade de Gênero, entre 2004 e 2007, ficando apenas depois da Europa.

Figura 1 ÍNDICE DE IGUALDADE DE GÊNERO (GEI) POR REGIÃO: EVOLUÇÃO ENTRE 2004 E 2007.

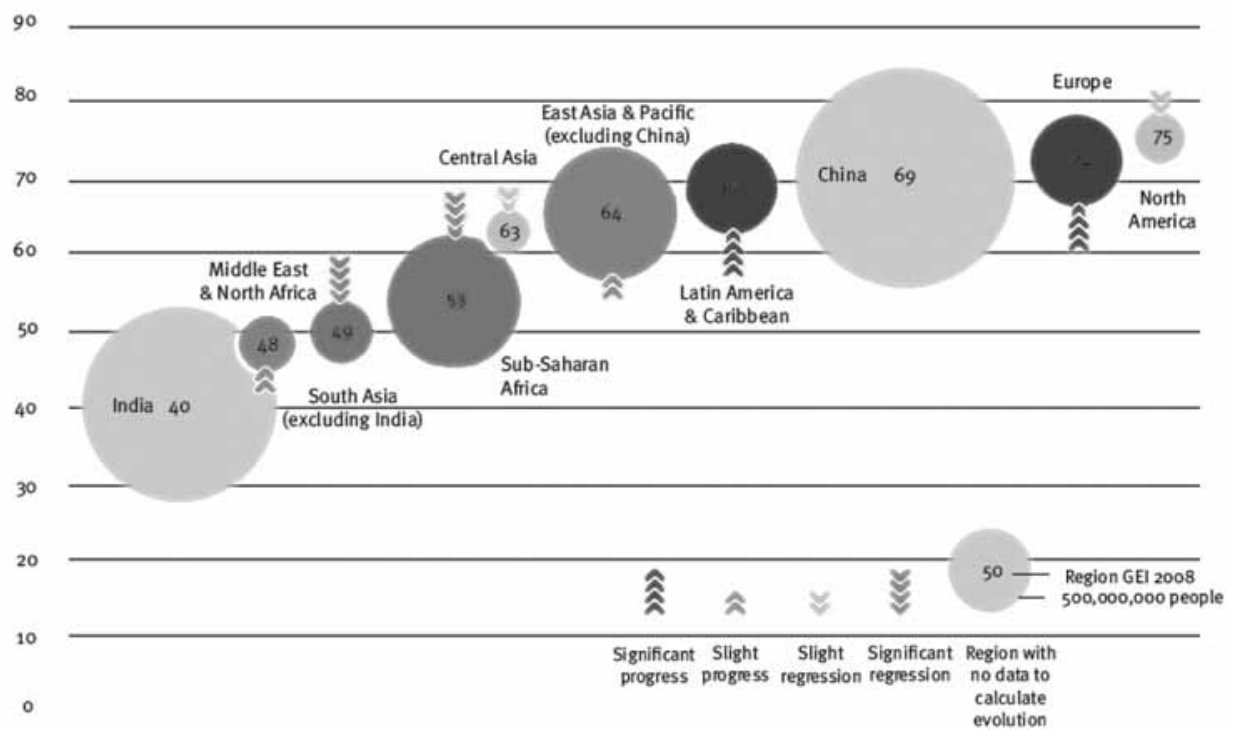

Fonte: Overseas Development Institute (2008). 'Gender and the MDGs: a gender lens is vital for pro-poor results'.

Apesar do otimismo que tais constatações podem despertar sobre a realidade local, estes avanços ainda não são suficientes, uma vez que eles coexistem com uma profunda segmentação ocupacional no mercado de trabalho. A discrepância entre homens e mulheres quanto à remuneração está se reduzindo de forma demasiado lenta e isto faz com que as habilidades que as mulheres desenvolvem a partir de sua educação não estejam sendo colocadas em prática na força produtiva na proporção

$6 \quad$ United Nations (2005). ECLAC. The Millennium Development Goals: a Latin-American Perspective. 
em que poderiam ser. Isto, por sua vez, faz com que haja um potencial latente para o crescimento econômico, que está sendo desperdiçado.? Percebe-se, dessa forma, que os benefícios que a educação das mulheres pode trazer para a economia só serão plenamente vistos na prática quando o trabalho da mulher for igualmente valorizado em relação ao do homem.

Na América Latina, há uma ampla cobertura dos níveis iniciais de instrução e houve uma recente expansão do número de matrículas no nível do ensino médio. Nove de cada dez meninos e meninas têm acesso à educação na América Latina do século XXI. No entanto, os níveis educacionais da região permanecem muito baixos se comparados a outras áreas. Com base nisso, Espíndola e León (2002) afirmam que os maiores desafios para alcançar os ODMs na América Latina são o combate à deserção escolar no ensino fundamental e a sua redução no ensino médio.

Nesta discussão, é impossível não mencionar a questão da qualidade do ensino - apesar de tal aspecto não estar incluso nos ODMs, o que é, inclusive, bastante questionável. É verdade que mais crianças estão tendo acesso à educação, mas a qualidade do ensino a que elas têm acesso deixa muito a desejar. A maioria dos países da América Latina não participa de nenhuma avaliação internacional uniforme, o que torna difícil comparar a região com outras áreas do mundo. Ainda assim, as escassas avaliações nacionais e internacionais disponíveis evidenciam que o aprendizado dos alunos permanece consideravelmente abaixo da média global. Alguns países da região, inclusive, apresentam posições próximas das últimas do ranking. ${ }^{8}$

Outra particularidade do contexto latino-americano tem a ver com contínuas práticas discriminatórias, profundamente arraigadas na mentalidade coletiva e relacionadas com o processo histórico específico da região, marcado pela colonização, escravidão e exploração externa. Isto é bem ilustrado em uma declaração feita pelo ex-Secretário Geral da ONU, Koffi Annan, na Cúpula Latino-Americana em 2003, enfatizando que alguns grupos sociais específicos sofrem de forma desproporcional na realidade regional. Pessoas de origem Africana ou indígena continuam sofrendo discriminação, independentemente de representarem quantitativamente uma maioria ou minoria na sociedade. Uma estratégia de desenvolvimento adequada não deve, segundo ele, ignorar as desigualdades históricas entre os diversos grupos sociais, as quais são ainda mais evidentes quando a desigualdade econômica se soma a divisões étnicas.

Conforme argumentam Torres e Mujica (2004), os ODMs são indubitavelmente uma oportunidade para criar as condições necessárias para maior igualdade no acesso a serviços pela população latino-americana. Os esforços dos governos dirigidos a alcançar os objetivos propostos não devem ser desviados de sua proposta original de 
eliminar (ou reduzir) as desigualdades às quais estão sujeitos importantes segmentos da sociedade na região.

Numa perspectiva bastante otimista, uma pesquisa realizada pelo BID apresentou que, como marcos de desenvolvimento para a América Latina, alcançar os ODMs até 2015 significaria tirar 118 milhões de pessoas da pobreza, colocar nove milhões de crianças nas escolas, fomentar a participação efetiva de milhões de mulheres e meninas na sociedade, elevar o nível de segurança pessoal da população feminina, além de muitos outros "benefícios típicos de sociedades mais inclusivas, que se disseminariam em toda a região e além".9

Esta declaração conduz este artigo a considerações sobre que tipo de ações têm sido desenvolvidas como respostas às ODMs dois e três e por quem. Serão sucintamente analisados os papéis desempenhados pela sociedade civil, pelo setor privado e pelos governos nacionais na consecução dos mencionados objetivos - com certa ênfase no último destes atores. Além disso, será explorado um exemplo de política pública que tem sido adotada por grande parte dos governos latino-americanos e que tem causado variados impactos sociais, além de reações controversas na opinião pública: a implementação de Programas de Transferência Condicional de Renda (PTCRs).

\section{RESPOSTAS POLÍTICAS E SEUS IMPACTOS NA REALIDADE LATINO-AMERICANA}

\section{O papel político da sociedade civil organizada, do setor privado e dos governos na efetivação das ODMs dois e três}

Os ODMs representam um chamado à ação coletiva que tem importantes consequências políticas para os governos nacionais da América Latina, em termos de elaboração de estratégias, prioridades e legislação, por exemplo. Governos, com a participação de legisladores e em diálogo constante com organizações da sociedade civil e do setor privado, têm a responsabilidade de adaptar os ODMs às respectivas realidades nacionais, levando em consideração condicionamentos históricos e sociológicos específicos. Este tópico irá, assim, analisar a função desempenhada por governos nacionais, ONGs e setor privado na concreção dos ODMs na América Latina.

\section{a) Governos nacionais}

Mesmo considerando que os ODMs só poderão ser plenamente atingidos se houver uma parceria entre todos os protagonistas da sociedade global, é possível afirmar que os governos nacionais são os que têm uma maior parcela de responsabilidade neste sentido. Afinal, são governos nacionais, representando seus respectivos Estados, que compõem a ONU e que formalmente se comprometeram a seguir a Declaração do Milênio.

9 Bouillon, Cesar P. (2005) The Millennium Development Goals in Latin America and the Caribbean: Progress, priorities and IDB support for their implementation. 
Para que os ODMs sejam alcançados na América Latina, é preciso que sejam forjadas sociedades mais coesas, reguladas por um contrato social explícito entre governo e cidadãos. É dizer, faz-se necessário um governo transparente, guiado por resultados, que possa ser responsabilizado por eventuais ilícitos praticados, que promova a solidariedade social e que disponha de cidadãos bem informados e conscientes de seus direitos e deveres. Entre os requisitos para isso, merecem especial atenção o desenvolvimento institucional, a reforma do setor público e o fortalecimento de capacidade estatística. No entanto, a região apresenta um nível demasiado baixo de confiança no governo. ${ }^{10}$

As principais áreas de reforma institucional são aquelas relacionadas à consolidação do sistema democrático, do Estado de Direito, da relação entre o Estado, o Mercado e a sociedade civil, assim como a administração pública (vide Figura 2). Além disso, os objetivos demandam investimentos públicos eficazes, instituições governamentais eficientes (em especial no que concerne à efetivação dos direitos sociais) e, em síntese, melhoria da coordenação interinstitucional, o que permitiria aos cidadãos que se apropriassem das políticas sociais.

\section{Figura 2. PRIORIDADES PARA REFORMA INSTITUCIONAL}

\begin{tabular}{|c|c|}
\hline A. Sistema Democrático & B. Estado de Direito \\
\hline Legisladores & Judiciário \\
\hline Sistema eleitoral e partidário & Acesso à justice \\
\hline Administração pública & Combate à corrupção \\
\hline Órgãos de monitoramento & Medidas alternativas de resolução de conflitos \\
\hline Descentralização do poder politico & Modernização normativa, substantiva e procedimental \\
\hline Sociedade civil & Segurança do cidadão \\
\hline \multicolumn{2}{|l|}{ Cultura democratic } \\
\hline C. Estado, Mercado e Sociedade & D. Administração Pública \\
\hline $\begin{array}{l}\text { Qualidade professional de instituições de administração } \\
\qquad \text { econômica }\end{array}$ & Serviço Público \\
\hline Instituições de regulação de mercado & Capacidade e eficiência fiscal e transparência nos gastos \\
\hline $\begin{array}{l}\text { Instituições para a formulação de políticas públicas ativas e } \\
\text { inclusivas }\end{array}$ & Coordenação de políticas públicas \\
\hline Instituições para a construção de consenso & Administração dos serviços públicos \\
\hline Governança ambiental & $\begin{array}{l}\text { Melhor uso de instituições de informação e tecnologia de } \\
\text { comunicação }\end{array}$ \\
\hline
\end{tabular}

Tradução própria com base em BID (2003) "Modernization of the State".

10 Buvinic', Mayra and Vélez, Carlos Eduardo (2003). 'The Millennium Development Goals in Latin America and the Caribbean' 
De acordo com Sachs e McArthur (2005), se a governança for adequada, a solução para alcançar os ODMs será um aumento de investimentos focalizados em setores e regiões. Este aumento em investimento, por sua vez, deve vir acompanhado de políticas sólidas e bem- estruturadas. No caso do ODM número dois (acesso universal ao ensino básico), a melhoria no sistema de ensino requer investimentos expressivos na infra-estrutura das escolas, em professores e materiais didáticos; mas também requer sistemas de administração que permitam uma maior transparência para fiscalizar orçamentos, assim como políticas públicas que encoragem o envolvimento dos pais e um sistema de administração das escolas que seja mais descentralizado.

De maneira análoga, no caso do Objetivo número 3 (promover a igualdade de gênero), investimentos precisam ser acompanhados de elaborações legislativas que protejam meninas e mulheres de violência e que garantam a elas direitos de propriedade e herança. Este aumento de intervenções e políticas, necessário para atingir os ODMs, requer investimentos de longo termo em sistemas de administração, infra-estrutura, treinamento, capacitação e manutenção de recursos humanos. Em muitos casos, ONGs serão as mais indicadas para promover alguns destes serviços.

\section{b) Organizações não governamentais}

A sociedade civil pode ser definida como um domínio no qual as pessoas "voluntarily associate with each other outside both their identities as citizens of a particular state and their role as consumers and producers" (Wapner, 2007: 254). A sociedade civil ganha importância política quando é mobilizada com vistas à mudança social. ONGs, por sua vez, são organizações duráveis e formais no âmbito da sociedade civil - isto é, configuram a sociedade civil organizada. Neste artigo, NGOs são adotadas como entidades representativas da sociedade civil como um todo.

Balbis (2001) enfatiza que, nas últimas três décadas, o papel das ONGs em relação ao desenvolvimento, boa governança e cooperação internacional têm ganharam muita importância. Na América Latina, como no resto do mundo, estas organizações vêm ganhando visibilidade, legitimidade e reconhecimento aos olhos da opinião pública, da mídia massificada, das agências internacionais e governos locais - ainda que sua base de representação, transparência e motivações são muitas vezes vistas como questionáveis.

Mesmo com o recente ganho de importância, a sustentabilidade destas organizações são consideravelmente dependentes das organizações para cooperação internacional e desenvolvimento, além de apresentarem uma crescente dependência de recursos governamentais. Com certa freqüência, as ONGs da região tornam-se meras entidades executoras de projetos promovidos pelos Estados e pelas agências de cooperação.

No entanto, Balbis defende que ONGs constituem um fenômeno inevitável na América Latina da atualidade, devido a suas contribuições ao combate de problemas sociais 
estruturais da região, além do esforço rumo a objetivos supostamente transcendentais, como seria o caso da igualdade de gênero e do acesso universal à educação básica.

\section{c) Setor Privado}

Uma das principais críticas contra os ODMs consiste na alegação de que são meras medidas paliativas, que não atacam as raízes dos problemas que se propõem a resolver. Por exemplo, é impossível resolver o problema da pobreza numa sociedade capitalista, modelo econômico que depende da manutenção da desigualdade social para o seu sucesso. Questiona-se, com isso, se seria possível conciliar harmoniosamente os interesses dos agentes capitalistas com os da sociedade como um todo.

Apesar deste relevante ponto contencioso, a ONU passou por consideráveis mudanças na sua relação com o setor privado, principalmente depois da administração de Koffi Annan, que trabalhou para o aprofundamento das relações entre a ONU e os líderes empresariais. Nas palavras de Murphy (2007: 270):

\section{"It urged developed countries to create a more conducive international trade and macroeconomic environment for development, as developing countries strengthened the rule of law and were urged to become more open to invite the private sector into the policy process".}

Atualmente, a posição dominante dentro da ONU é de que o setor privado pode desempenhar um papel crucial na promoção da autonomia das mulheres e no combate à discriminação de gênero. O Secretário-Geral da ONU, Ban Ki Moon, enfatiza a importância do "innovative spirit of the private sector and public-private partnerships" em alcançar progresso sustentável nesta área (United Nations, Private Sector Forum on Millennium Development Goals: 2010).

Como organização internacional intergovernamental que é, a ONU representa diretamente a sociedade internacional de Estados. No entanto, para assegurar a representação dos "povos das Nações Unidas", conforme estabelecido na Carta da ONU, é fundamental que se construa uma arena de intercâmbio e ação conjunta entre os diversos atores sócio-políticos que compõem a sociedade internacional. Afinal, os interesses estatais nem sempre converge com os interesses da população e, portanto, é preciso buscar uma orientação mais compreensiva e não-sectária no combate aos problemas globais ${ }^{11}$.

Exemplos de respostas políticas adotadas pelos Estados latino-americanos, com ênfase nos Programas de Transferência Condicional de Renda (PTCRs).

Tendo em vista o progresso feito no que tange à promoção do acesso à educação e à redução da desigualdade de gênero, alguns programas governamentais e políticas

11 Wapner, Paul (2007). 'Civil Society' em The Oxford Handbook of the United Nations 
públicas podem ser enfatizados, devido ao seu impacto na região e à possibilidade de servirem como um modelo para outros países latino-americanos.

Espíndola e León (2002) sugerem que, junto à construção de escolas em zonas rurais isoladas e à melhoria da infra-estrutura das escolas, programas governamentais, como o Bolsa Escola, no Brasil, o Liceo para Todos, no Chile, e o Progresa, no México, tiveram impactos importantes na redução da taxa de deserção escolar. Estes programas oferecem auxílio financeiro, materiais escolares gratuitos e merenda escolar também gratuita. Além disso, os autores sustentam que houve uma valorização da educação por parte dos pais, uma vez que esta se tornou uma das poucas (quando não a única) alternativas para melhorar as oportunidades de emprego nos grandes centros urbanos.

Programas de Transferência de Renda (PTRs) também desempenharam um papel central em aumentar o acesso da população de baixa renda à educação. Estes programas fornecem certo valor monetário mensalmente para famílias classificadas como pobres ou extremamente pobres, com o objetivo de melhorar as condições de saúde e educação nesta camada da população. Garrett, Bassett e Marini (2008) afirmam que tendencialmente os PTRs objetivam minimizar problemas sociais crônicos que afetam de maneira mais drástica a população de baixa renda. Alguns dos PTRs ainda buscam aprimorar o capital humano, em especial ao tentar melhorar o acesso à educação entre as camadas mais pobres da população.

PTRs podem ser divididos em dois tipos: condicionais (PTCRs) ou incondicionais (PTIRs). Estes últimos normalmente não são recomendados pelos agentes monetários de desenvolvimento, ainda que haja algumas experiências em curso na América Latina, como é o caso do Equador com o programa "Bono de Desarrollo Humano", lançado em 2003. Mais comumente, porém, exigem-se dos beneficiários certos requisitos - um dos mais comuns é matrícula e a frequência das crianças na escola. O que, de forma geral, distingue os programas dos diferentes países é a escala ou a forma em que adotam estes requisitos. Na Colômbia, por exemplo, as crianças devem estar matriculadas nas escolas entre as idades de 7 a 18 anos, enquanto na Nicarágua esta faixa vai dos 6 aos 13 anos de idade. Embora estes programas sejam promovidos por governos nacionais, muitos deles são apoiados por bancos de desenvolvimento, notadamente o BID e o Banco Mundial (Mattei, 2009).

A tabela acima fornece exemplos de PTCRs que vem sendo implementados na América Latina. É possível identificar que, independentemente da variedade de detalhes (como o valor monetário que é concedido às famílias ou a a cobertura dos programas nas realidades locais), a maioria dos PTCRs adotam como condicionalidades a matrícula e a freqüência das crianças nas escolas. Isto explica porque tais programas, cujo objetivo imediato é promover a distribuição de renda e a erradicação da pobreza (ODM número um), vêm apresentando expressivos impactos na expansão do acesso das crianças -tanto meninos quanto meninas (ODM número três) - ao ensino básico (ODM número dois) na América Latina. 


\section{Tabela 1 EXEMPLOS DE PROGRAMAS DE TRANSFERÊNCIA CONDICIONAL DE RENDA NA AMÉRICA LATINA (PTCRS)}

\begin{tabular}{|c|c|c|c|c|c|c|}
\hline País & PTCR & Ano & Objetivos & Valor & Condicionalidades & Cobertura \\
\hline Brasil & Bolsa Família & 2003 & $\begin{array}{l}\text { Transferência de } \\
\text { renda para famílias } \\
\text { de baixa renda }\end{array}$ & $\begin{array}{c}\text { De } R \$ 50 \text { a } \\
R \$ 95\end{array}$ & $\begin{array}{l}\text { Matrícula e frequência das } \\
\text { crianças na escola; } \\
\text { Assistência médica regular } \\
\text { para as crianças }\end{array}$ & $\begin{array}{l}11 \text { milhões de } \\
\text { famílias em } \\
2008\end{array}$ \\
\hline Argentina & $\begin{array}{l}\text { Jefes de } \\
\text { Hogar }\end{array}$ & 2001 & $\begin{array}{l}\text { Transferência de } \\
\text { renda para famílias } \\
\text { de baixa renda }\end{array}$ & 150 Pesos & $\begin{array}{l}\text { Matrícula e frequência das } \\
\text { crianças na escola; } \\
\text { Assistência médica regular } \\
\text { para as crianças }\end{array}$ & $\begin{array}{l}1.5 \text { milhão de } \\
\text { famílias em } \\
2008\end{array}$ \\
\hline Paraguai & Tokepora & 2005 & $\begin{array}{l}\text { Transferência de } \\
\text { renda para famílias } \\
\text { de baixa renda }\end{array}$ & US\$ 21 & $\begin{array}{l}\text { Matrícula e frequência das } \\
\text { crianças na escola; } \\
\text { Assistência médica regular } \\
\text { para as crianças }\end{array}$ & $\begin{array}{l}13 \text { mil famílias } \\
\text { em } 2008\end{array}$ \\
\hline Chile & $\begin{array}{l}\text { Chile } \\
\text { Solidario }\end{array}$ & 2002 & $\begin{array}{l}\text { Transferência de } \\
\text { renda para famílias } \\
\text { de baixa renda }\end{array}$ & $\begin{array}{c}\text { De US\$ } 15 \\
\text { a US\$30 }\end{array}$ & $\begin{array}{l}\text { Matrícula e frequência das } \\
\text { crianças na escola; } \\
\text { Assistência médica regular } \\
\text { para as crianças }\end{array}$ & $\begin{array}{l}262 \text { mil famílias } \\
\text { em } 2008\end{array}$ \\
\hline Colômbia & $\begin{array}{c}\text { Famílias en } \\
\text { Acción }\end{array}$ & 2001 & $\begin{array}{l}\text { Transferência de } \\
\text { renda para famílias } \\
\text { de baixa renda }\end{array}$ & $\begin{array}{c}\text { De US\$ } 20 \\
\text { a US\$38 }\end{array}$ & $\begin{array}{l}\text { Matrícula e frequência das } \\
\text { crianças na escola; } \\
\text { Assistência médica regular } \\
\text { para as crianças }\end{array}$ & $\begin{array}{l}300 \text { mil famílias } \\
\text { em } 2008\end{array}$ \\
\hline Peru & $\begin{array}{c}\text { Programa } \\
\text { Juntos }\end{array}$ & 2005 & $\begin{array}{l}\text { Transferência de } \\
\text { renda para famílias } \\
\text { de baixa renda }\end{array}$ & US\$33 & $\begin{array}{l}\text { Matrícula e frequência das } \\
\text { crianças na escola; } \\
\text { Assistência médica regular } \\
\text { para as crianças }\end{array}$ & $\begin{array}{l}355 \text { mil famílias } \\
\text { em } 2008\end{array}$ \\
\hline México & $\begin{array}{l}\text { Progresa } \\
\text { and } \\
\text { Oportunidades }\end{array}$ & $\begin{array}{l}1997 \\
2002\end{array}$ & $\begin{array}{l}\text { Transferência de } \\
\text { renda para famílias } \\
\text { de baixa renda }\end{array}$ & $\begin{array}{l}\text { Até } 580 \\
\text { Pesos }\end{array}$ & $\begin{array}{l}\text { Matrícula e frequência das } \\
\text { crianças na escola; } \\
\text { Assistência médica regular } \\
\text { para as crianças }\end{array}$ & $\begin{array}{l}5 \text { milhões de } \\
\text { famílias em } \\
2007\end{array}$ \\
\hline
\end{tabular}

Fonte: Adaptado de'Notas sobre os Programas de Transferência de Renda da América Latina'(Mattei, 2010).

Muitos dos PTCRs da América Latina escolhem a mulher como recipiente primário da transferência de renda, devido ao papel que desempenha como mãe, frequentemente a principal ou mesmo única responsável pelas crianças. De acordo com Soares e Silva (2010), pesquisas mostram que é mais provável que o dinheiro gasto pela mulher seja direcionado ao bem-estar de seus filhos.

Alguns PTCRs também tentam combater algumas vulnerabilidades específicas da população feminina, como forma de promover a igualdade de gênero. Algumas das ações neste sentido são: o provimento de mais dinheiro para meninas em idade escolar, as quais apresentam maior risco de abandono dos estudos, especialmente quando 
atingem a educação secundária; o fornecimento de cuidados médicos gratuitos para gestantes e mulheres em período de amamentação; a tentativa de promover novas formas de interação comunitária entre mulheres beneficiárias dos PTCRs, notadamente da zona rural, onde o governo passa a oferecer treinamentos, capacitações e eventos beneficentes, por exemplo.

Ainda segundo Soares e Silva (2010), pesquisas quantitativas avaliaram o poder de barganha das mulheres através de um índice baseado numa combinação de variáveis relacionadas ao processo de tomada de decisão no ambiente doméstico. O resultado mostrou que no Brasil, por exemplo, as beneficiárias do Programa Bolsa Família apresentaram maior poder de barganha junto a suas famílias do que as mulheres não contempladas pelo programa. Entretanto, uma pesquisa similar apontou que na Colômbia, com o Programa Familias en Acción, não houve acréscimo do poder de barganha das mulheres beneficiárias.

Estudos de caráter qualitativo no Brasil e no Chile evidenciam impactos positivos na identidade das beneficiárias. No Brasil, estes impactos parecem originar-se do papel que estas mulheres passam a desempenhar como consumidoras. Ao possuírem mais recursos financeiros, decresce a dependência que elas tendem a apresentar em relação aos companheiros ou cônjuges. Esta mudança na alocação do poder econômico dentro do ambiente familiar confere à mulher não apenas o poder de escolha sobre o que se consome, mas também uma maior auto-estima, o que a encoraja a negociar e dialogar mais com o companheiro, com o fim de tomar decisões conjuntas. No Chile, este senso de identidade parece resultar do componente familiar presente no programa Chile Solidario. Beneficiárias passam a se sentir confiantes para se enxergarem como indivíduos e não apenas como mães ou esposas. É importante ressalvar, porém, que o aumento da auto-confiança e autonomia das mulheres não quer dizer necessariamente que seus companheiros estão dispostos a dividir com elas as tarefas domésticas, tradicionalmente vistas como femininas, o que permanece sendo uma forma de opressão contra as mulheres.

Apesar destas avaliações positivas, há autores que não vêem os PTCRs como as estratégias mais eficazes para o combate à desigualdade de gênero. Exemplos são Molyneux (2009) e Jenson (2009), que afirmam que PTCRs reforçam papéis tradicionais de gênero, no lugar de mitigá-los. Afinal, a mulher é usualmente a recipiente primária da transferência de renda por conta do estereótipo feminino de guardiã das crianças. A perspectiva de investimento social, que está por trás de grande parte dos PTCRs, tem como foco o bem-estar da criança -sendo a mulher vista como mero instrumento para atingir tal fim. De fato, os PTCRs não foram elaborados com o fim primário de suprir as necessidades das mulheres. Em certas situações, os programas podem fazer com que seja necessário escolher entre o bem-estar da mulher ou o da criança, além de reforçar estereótipos de gênero, o que pode representar um retrocesso em relação às conquistas feministas das últimas décadas.

Em relação a estas constatações, Soares e Silva (2010) fazem algumas sugestões para evitar estes efeitos indesejáveis. A primeira delas é que a linguagem usada nos PTCRs 
poderia ser reformulada. A segunda é que os programas poderiam criar oportunidades de discussão sobre os papéis de gênero tradicionais, no que tange à criação e aos cuidados de saúde das crianças, dentro do ambiente familiar. Além disso, o contexto de proteção social -do qual os PTCRs são (ou deveriam ser) apenas um elemento- deveria disseminar a construção de creches gratuitas e fomentar oportunidades econômicas para as mulheres beneficiárias, de forma que a autonomia econômica e a crescente capacidade de sociabilização possam ser atingidas através de uma maior participação no mercado de trabalho e maior potencial de remuneração, para aquelas mulheres que assim desejarem.

É importante mencionar que muitos desses programas não foram formuladas como respostas diretas aos ODMs. Alguns dos programas, inclusive, são prévios à própria Declaração do Milênio, que entrou em vigor no ano 2000. Mesmo assim, tais programas vêm tendo relevantes impactos na realidade latino-americana, contribuindo para os ODMs dois e três, entre outros.

\section{CONCLUSÃO}

As dimensões complementares dos ODMs aqui analisados têm sido inclusos na legislação de muitos países e também em tratados internacionais. Portanto, os ODMs podem ser definidos como um endosso da igualdade de gênero como um dos objetivos centrais da agenda internacional, assim como um aspecto complementar de metas assumidas em conferências prévias.

O reconhecimento político por parte da sociedade internacional quanto à importância da igualdade de gênero, não apenas como um fim em si mesma, mas também como meio para o desenvolvimento, é um ponto de partida decisivo. De maneira similar, a percepção tanto do valor instrumental quanto inerente da garantia do acesso universal ao ensino básico é fundamental para a solução de muitos problemas globais.

A experiência latino-americana evidencia, com seus recentes progressos, que os ODMs dois e três são alcançáveis. Porém, também evidencia que apenas suficiente vontade política, unida ao desenvolvimento econômico, pode levar a avanços quanto à igualdade de gênero na educação - os quais possam ser aferidos em outros âmbitos de relevância social, política e econômica, como o mercado de trabalho e o parlamento. Ademais, a experiência da região em tela demonstra que alguns aspectos cruciais para o desenvolvimento regional não foram levados em consideração nos ODMs, mas precisam ser objeto de atenção se a meta é efetivar uma mudança social significativa. É o caso da qualidade da educação, das taxas de deserção escolar e das práticas discriminatórias enraizadas na cultura e história latino-americanas.

Levando isso em conta, relatórios das Nações Unidas, especificamente da Comissão Econômica para América Latina e o Caribe (2005), enfatizam que a meta de "eliminar a disparidade de gênero na educação primária e secundária, preferencialmente até 2005, e em todos os níveis de educação até 2015" deve ser interpretada em relação com o 
mosaico mais amplo de políticas anti-discriminatórias, focalizadas nas manifestações mais críticas da desigualdade de gênero, como a discriminação no mercado de trabalho, as insuficiências no acesso a serviços públicos (em especial serviços de saúde sexual e reprodutiva), desigualdade na distribuição das tarefas domésticas, violência contra a mulher e a deficiente representação feminina na política.

Apesar da Declaração do Milênio ter sido formalmente assinada por Estados, a concreção dos ODMs demanda um engajamento coletivo e uma cooperação entre todos os agentes políticos da sociedade, incluindo a sociedade civil, o setor privado e os governos locais.

Dentre os programas adotados na região, uma política pública que teve notáveis impactos na democratização da educação entre a população de baixa renda, incluindo ambos os gêneros, foi a implementação dos Programas de Transferência Condicional de Renda. Embora inicialmente direcionados à erradicação da pobreza, as condicionalidades exigidas pelos programas incentivaram amplamente a matrícula e freqüência de crianças em instituições de ensino básico na região.

Estas considerações são relevantes para pautar os avanços que devem ser alcançados pela América Latina nos próximos anos, uma vez que elas possibilitam a compreensão do panorama geral da região quanto à educação básica e igualdade de gênero, além de indicarem peculiaridades latino-americanas. As considerações apresentadas neste artigo também são importantes para a identificação dos pontos fracos e fortes dos ODMs como estratégia de desenvolvimento internacional. Além disso, demonstram de que forma os ODMs dois e três estão relacionadas e levam à conclusão de que tais objetivos só poderão ser alcançados com uma abordagem pragmática, compreensiva e integrada, levada a termo por todos os atores da sociedade internacional.

\section{BIBLIOGRAFIA}

Abu Ghaida, Dina e Klasen, Stephan (2004): 'The costs of missing the Millennium Development Goal on Gender Equity', em World Development, Vol. 32, No. 7, pp. 1075-1107.

Barroso, Carmem (2004): 'Metas de desenvolvimento do milênio, educação e igualdade de gênero', em Cadernos de Pesquisa, Vol. 34, No. 123, pp. 573-582.

Bouillon, Cesar P. et al. (2005): The Millennium Development Goals in Latin America and the Caribbean: progress, priorities and IDB support for their implementation'. Inter-American Development Bank. Washington DC. Acessado em: 12.04.2011. Disponível em: [http://idbdocs.iadb.org/wsdocs/getdocument.aspx?docnum=591088].

Buvinic, Mayra e Vélez, Carlos Eduardo (2003): 'The Millennium Development Goals in Latin America and the Caribbean'. United Nations. New York. Disponível em: [http://WwW.undp.org.tt/MDG/MDGs/n\%20LAC\%20ENG.pdf]. Acessado em: 15.11.2010. 
Espíndola, Ernesto e León, Arthur (2002): 'Deserción escolar en América Latina: um tema prioritario para la agenda regional', em Revista Iberoamericana de Educación, No. 30, pp. 39-62.

Garret, J. et al. (2008): 'Designing CCT Programs to improve nutrition impact: principles, evidence, and examples.' III Seminario Internacional Transferencias Condicionadas. Santiago de Chile: FAO/United Nations.

Jenson, Jane (2009): Lost in Translation:The Social Investment Perspective and Gender Equality' em Social Politics: International Studies in Gender, State \& Society, Vol. 16, No. 4, pp. 446-483.

Jones, Nicola et al. (2008): 'Gender and the MDGs: a gender lens is vital for pro-poor results' em Briefing Paper, No. 42. Overseas Development Institute [wWw.odi.org.uk] Acessado em: 15.11.2010. Londres.

Mattei, Lauro (2010): 'Notas sobre Programas de Transferência de Renda na América Latina'. Texto para discussão, No 10. Florianópolis: Universidade Federal de Santa Catarina: Instituto de Estudos Latino-americanos.

Molyneux, Maline (2009):'Conditional Cash Transfers: A Pathway to Women's Empowerment?' Pathways Brief 5. London: DFID.

Murphy, Craig N. (2007): 'Private Sector', em The Oxford Handbook on the United Nations, Thomas G. Weiss e Sam Daws (comps.), pp. 264-274, Oxford: Oxford University Press.

Laurenti, Ruy (2005):'Objetivos de Desenvolvimento do Milênio', em Revista da Associação Médica Brasileira, Vol. 51, No. 1, pp. 3-4.

Saith, Ashwani (2006): 'From Universal Values to Millennium Development Goals: Lost in Translation'em Development and Change, Vol. 37, No. 6, pp. 1167-1199.

Soares, Fábio V. e Silva, Elyda (2010): 'Conditional Cash Transfer Programmes and Gender Vulnerabilities: Case Studies of Brazil, Chile and Colombia', em IPC-IG Working Paper. Brasilia: International Policy Center for Inclusive Growth.

Torres, Cristina e Mújica, Oscar J. (2004): 'Salud, Equidad y Objetivos de Desarrollo del Milénio' em Pan-American Journal of Public Health, Vol. 15, No. 6, pp. 430-439.

United Nations: Economic Commission for Latin America and the Caribbean (2005): 'The Millennium Development Goals: A Latin-American Perspective.' Disponível em: [http://www.eclac.org/cgibin/getProd.asp?xm/=/publicaciones/xml/4/28354/P28354. xm/\&xsl=/dds/tpl-i/p9f.xs/\&base=/brasil/tpl/top-bottom.xslt]. Acesso em: 12.04 .2011 
United Nations: Private Sector Forum on the Millennium Development Goals (2010): 'Thematic Discussion Briefing Note: Empowering Women and Achieving Equality'. Disponível em: [http://www.unglobalcompact.org/docs/issues_doc/un_business_partnerships/UNPSF2010/Women_Equality.pdf] Acesso em: 12.04.2011

United Nations: Millenium Development Goals (2010): 'We can end poverty 2015: Millenium Development Goals - a gateway to the UN's work on the MDGs'. Disponível em: [http://www.un.org/millenniumgoals/] Acesso em: 01.10.2010.

Wapner, Paul (2007): 'Civil Society', em The Oxford Handbook on the United Nations, Thomas G. Weiss and Sam Daws (comps.) pp. 254-263, Oxford: Oxford University Press. 